\title{
Design and development of a scale of perceived barriers to self-care in patients with type 2 diabetes mellitus: an exploratory factor analysis
}

\author{
Ali Ramezankhani ${ }^{1}$, Hamid Soori ${ }^{2}$, Fatemeh Alhani $^{3}$, Ali Moazemi Goudarzi ${ }^{4}$
}

\author{
${ }^{1}$ Ph.D., Professor, Department of Public Health, Faculty of Health, Shahid Beheshti University of Medical Sciences, \\ Tehran, Iran \\ ${ }^{2}$ Ph.D., Professor, Safety Promotion and Injury Prevention Research Center, Department of Epidemiology, Faculty \\ of Health, Shahid Beheshti University of Medical Sciences, Tehran, Iran \\ ${ }^{3}$ Ph.D., Associate Professor, Department of Nursing, Faculty of Medical Sciences, Tarbiat Modares University, \\ Tehran, Iran \\ ${ }^{4}$ Ph.D. Candidate, Department of Public Health, Faculty of Health, Shahid Beheshti University of Medical Sciences, \\ Tehran, Iran
}

\section{Type of article: Original}

\begin{abstract}
Introduction: Despite the importance of perceived barriers against self-care in diabetic patients, the role of this factor is rarely addressed in the improvement of self-care behaviors of Iranian patients. The lack of appropriate instruments that fit demographic properties of Iranian society is one reason. The aim of this study was to develop and validate the scale of perceived barriers to self-care in patients with type 2 diabetes mellitus.

Methods: This cross-sectional study conducted on 400 patients with type 2 diabetes who were covered by the health centers in Isfahan (Iran) in 2015. A 22-item, researcher-made instrument was designed; the face and content validities of the instrument were examined through obtaining the opinions of an expert panel before administering the instrument in the study. Also, the exploratory factor analysis was used to investigate the instrument's validity. Cronbach's alpha was employed to measure its internal consistency (reliability). To examine the validity of the final scale, the mean scores of perceived barriers in patients with appropriate and inappropriate self-care behaviors were compared.

Results: The research sample was comprised of 240 women $(60 \%)$ and 160 men $(40 \%)$. The mean value of the content validity index was 0.84 . The results of factor analysis confirmed the validity of the 11 items and 3 factors of the developed scale. The factor loading ranged from 0.46 to 0.78 . These three factors together explained $40.28 \%$ of the total variance. The overall reliability coefficient of the instrument was 0.79 , ranging from 0.82 to 0.93 for three factors.

Conclusion: According to the results, the developed scale was a valid and reliable instrument for examining the barriers perceived by the patients. The findings of this research can help health policy makers in planning to facilitate the self-care behaviors as the most vital factor in diabetes control.
\end{abstract}

Keywords: diabetes mellitus, self-care, perceived barriers, validity, reliability

\section{Introduction}

Demographic changes and cultural transition, along with aging in developing countries, have turned diabetes into a global epidemic. The World Health Organization (WHO) announced diabetes as a hidden epidemic and, in 1993, asked all countries to confront the epidemic (1). Despite an international commitment and availability of a variety of drugs to treat and prevent long-term complications of diabetes, reported statistics on the prevalence of diabetic complications are very disappointing. This is an important health problem in the life quality of diabetic patients (2). Studies have shown that only a small portion of chronic diseases, such as diabetes, are cared for and treated by

\section{Corresponding author:}

Ali Moazemi Goudarzi, Department of Public Health, Faculty of Health, Shahid Beheshti University of Medical Sciences, 198353-5511, Tehran, Iran. Tel: +98.2122432040, E-mail: moazemiali190@yahoo.co.uk

Received: October 01, 2015, Accepted: November 11, 2015, Published: November 2015

iThenticate screening: October 13, 2015, English editing: November 05, 2015, Quality control: November 15, 2015 (C) 2015 The Authors. This is an open access article under the terms of the Creative Commons Attribution-NonCommercialNoDerivs License, which permits use and distribution in any medium, provided the original work is properly cited, the use is non-commercial and no modifications or adaptations are made. 
specialized staff, and the patients and their families have significant roles in the management of chronic diseases, such as diabetes $(3,4)$. Achievement in diabetes control depends largely on self-care, as the majority of diabetes care processes are done by the patient. According to the available studies, the most important cause of mortality and complications among diabetic patients is negligence in self-care behaviors (5). Self-care is a practice in which one's knowledge, skill, and capability are used as a resource to make the patient capable of exhibiting self-care behaviors independently. Here, the term independently refers to making decisions about oneself and relying on oneself. This decision-making may include consulting and asking for specialized or non-specialized help from either a specialist or non-specialist $(6,7)$. Several studies across the world used different methods to show that the self-care behaviors are the most important form of initial care. It is estimated that 65 to $85 \%$ of all health care practices are done independently by the patient and her/his family, using traditional and non-medical methods or common treatments (6). The self-care dimensions include a wide range of self-care behaviors as follows: blood glucose monitoring and controlling, insulin therapy and oral diabetic medications, exercise and physical activities, nutrition and diet, prevention from acute diabetes complications, including nephropathy and retinopathy, foot care, smoking cessation, and other health-related behaviors (8). There are different factors that directly and indirectly affect self-care behaviors of diabetic patients, including: biological, psychological, economic, social, cultural, and health-medical care systems. Due to the importance of self-care activities in disease management, a complete understanding of selfcare-related factors in diabetic patients is highly required (9). According to the literature, the barriers perceived by the patients are the most important predictors of self-care in diabetic patients (10). According to behavioral models, the constructs of the perceived barriers can be placed within the value expectation framework. It means that if the perceived barriers overcome the predicted interests, the probability of such behaviors will decrease. In fact, people's behaviors are determined by the effect of balance or imbalance between the perceived positive and negative forces on their health behavior (11). Despite the importance of perceived barriers to self-care in diabetic patients, our study showed that the role of this factor is rarely addressed in the improvement of self-care behaviors of Iranian patients. The lack of appropriate instruments that fit demographic properties of Iranian society is one reason. This study was done aiming at developing and investigating the scale of perceived barriers to self-care in patients with type 2 diabetes.

\section{Material and Methods}

\subsection{Study setting and sampling}

This was a cross-sectional study. The study population included all patients with type 2 diabetes covered by the health centers in Isfahan. To ensure about the sample size required for exploratory factor analysis was attained, Comery and Lee's recommendation was used, and the sample size of 400 subjects was chosen (12). In this study, the multi-stage random sampling method was used. The city of Isfahan has two health centers with similar population distributions. These centers have 11 affiliated health centers across the city, out of which three centers were selected from each main center (a total of six affiliated centers) using simple random sampling. Then, a list of eligible diabetic patients was prepared. After that, the subjects were selected according to the research population/sample size ratio. The selected subjects got familiar with the research objectives when visiting the centers, and they volunteered to be included in the study. In the case of not showing up in one month, alternative subjects were contacted and informed about the research objectives. Then, they were invited to participate in the study after obtaining their oral consent. The research instrument was self-report and completed by the patients. To prevent the loss of data, all parts of the questionnaire were reviewed by the researcher. In case of any loss of data, the questionnaires were returned to the respondent so they could complete them. Completion of questionnaires was done over a two-month interval.

\subsection{Selection criteria}

Inclusion criteria were patients with definitive diagnosis of the disease by a physician, record in the respective health center, no chronic or severe complications, age range of 25-60, willingness to participate in the study, and no dementia. Exclusion criteria were unwillingness of the patients to continue the study and diagnosis of certain psychological and mental illnesses during the study.

\subsection{The Instrument}

The instrument used in this study had three parts:

1) demographic specifications, including age, gender, marital status, educational attainment, diabetes history in the family, duration of infection, and type of treatment.

2) To investigate the self-care behavior of diabetic patients, the Summary of Diabetes Self-Care Activities (SDSCA) Measure (Toobert et al., 2000) was employed (13). This is a 14-item scale in which scoring is based on the number 
of self-care activities performed in a week (ranging from 0-7). The SDSCA measure includes items assessing general diet (4 items), physical exercise (2 items), blood-glucose testing ( 2 items), foot care ( 2 items), medication regiment (3 items), and smoking ( 1 item). In the core study by Toobert et al., a Cronbach's alpha of 0.76 was reported for this scale. The scoring process was as follows: the mean scores of items 1-2, 3-4, 5-6, 7-8, 9-10, 11-13, and 0-1 were used for general diet, specific diet, exercise, blood-glucose testing, foot care, medication regiment, and smoking, respectively. The reliability and validity of this instrument were measured, and the reliability was reported as $0.69-0.91(14)$.

3) The researcher-made, self-care barrier inventory was comprised of 22 items, scored on a 5 -point Likert scale $(1=$ strongly agree, 2 = agree, 3 = neutral, $4=$ disagree, $5=$ strongly disagree).

\subsection{Validity}

2.4.1. Developing the Items: First, a comprehensive body of literature was reviewed to identify different aspects of perceived barriers and to develop the questions. Then, 22 items were developed to be included in the perceived barriers instrument. In doing this, it was attempted to use clear writing and appropriate wording. In this regard, the opinions of two experts in Persian literature were used.

2.4.2. Face Validity: The Face validity was measured in qualitative and quantitative stages. In the former stage, the Face validity, items consistency and relations, uncertainty and misinterpretations, and difficulty of concepts were investigated by four physicians, five health education and promotion specialists, and two social specialists. In addition, the researcher used the opinions of experts to correct each case. In the second stage, the impact factor was measured. Moreover, the experts were asked to categorize each item of the questionnaire on a 5-point Liker scale in terms of their importance (ranging from $5=$ very important to $1=$ not important at all). Then, the Impact Score for each item was calculated based on the formula. Items with Impact Score $>1.5$ were maintained and considered eligible for the next analyses.

2.4.3. Content Validity: The criteria for content validity were as follows: 1) items relevant to the main concept under investigation, 2) items reflecting the investigated population, and 3) items reflecting the objective of measurement instrument. To assess the content validity, both quantitative and qualitative methods were used (15). In the former technique, to ensure that the most important and accurate concepts were selected, the content validity ratio (CVR) was used. In addition, to determine the best method for measuring the items, the content validity index was employed. In the qualitative content analysis, some experts were interviewed and asked for their corrective opinions in terms of grammar, appropriateness and understandability of words, appropriate scoring, time required for completing the questionnaire, consistency of the selected aspects, and location of items after carefully studying the instrument. After obtaining these data, the researcher started to develop the final version of the instrument.

2.4.4. Construct Validity: The exploratory factor analysis with principal component method and Varimax rotation was used for investigating the construct validity. To inspect for sampling adequacy and between-variable correlation, the Kaiser-Meyer-Olkin (KMO) test and Bartlett's test of sphericity were used. In this study, the turning point of 0.4 was considered as the minimum factor loading required for maintaining each statement in the factors elicited from the factor analysis.

2.4.5. Validity of the Final Scale of Perceived Barriers: To examine the validity of the final scale, the mean scores of barriers perceived by patients with appropriate and inappropriate self-care behaviors were compared, assuming higher scores for the former group. To this end, the mean score of self-care in patients was inspected on the basis of Toobert's inventory.

\subsection{Reliability}

The internal consistency technique was used for measuring the reliability of the questionnaire. The internal consistency refers to the degree of correlation between the items of a questionnaire in a certain index. The most common method used for this purpose is Cronbach's alpha. According to this method, an instrument is considered adequately reliable when the Cronbach's alpha is equal to or larger than 0.7 (16). To determine the internal consistency of the instrument, the Item-Total Correlation method, which inspects the consistency of each item with the whole instrument, was used to decide on the removal of some questions.

\subsection{Research ethics}

Before initiation of the study, the approval of the Ethics Committee of Shahid Beheshti University of Medical Sciences (Ref. No.: 1393-1-85-13790) was obtained. In addition, obtaining written consent, protecting the confidentiality of information, and observing the subjects' rights of quitting the study were taken into consideration. 


\subsection{Data Analysis}

Research data were analyzed with SPSS 21, using descriptive statistical methods, Cronbach's alpha, Pearson correlation, KMO test, Bartlett's test of sphericity, and Varimax rotation.

\section{Results}

The research sample was comprised of 400 participants, including 240 women (60\%) and 160 men (40\%). The age range of the participants was 27-60 with the mean of $52.53 \pm 7.63$. In addition, $97.3 \%$ of the subjects were married (Table 1). The face validity measured by the Impact Score for each item showed that three items of the questionnaire had the impact factor $<1.5$; therefore, these three items were removed in this stage. Among the 19 items under validity analysis on the basis of experts' opinions, three items were removed for the scores 0.79 . The mean value of the content validity index was 0.84 . The KMO test was done before performing exploratory factor analysis and to ensure about the sampling adequacy. The KMO value 0.71 indicated an appropriate adequacy of data for the analysis of the principal components. Similarly, the Bartlett's test of sphericity was significant $(p<0.001,311.36)$, indicating adequate correlation between variables for analysis. The exploratory factor analysis with Varimax rotation was applied on 16 items. Investigation into the results led to the categorization of items in three factors with an eigenvalue $>1$.

Table 1. Characteristics of the Participants in the Study

\begin{tabular}{|l|l|l|}
\hline \multicolumn{2}{|l|}{ Variables } & Value, n (\%) \\
\hline Age (year) & $20-29$ & $4(1 \%)$ \\
\cline { 2 - 3 } & $30-39$ & $26(6.5 \%)$ \\
\cline { 2 - 3 } & $40-49$ & $62(15.5 \%)$ \\
\cline { 2 - 3 } & $50-60$ & $308(77 \%)$ \\
\hline \multirow{5}{*}{ Gender } & Male & $160(40 \%)$ \\
\cline { 2 - 3 } & Female & $240(60 \%)$ \\
\hline \multirow{3}{*}{ Marital status } & Married & $389(97.3 \%)$ \\
\cline { 2 - 3 } & Single & $11(2.8 \%)$ \\
\hline Family income & Very Low & $61(15.3 \%)$ \\
\cline { 2 - 3 } & Low & $174(68.5 \%)$ \\
\cline { 2 - 3 } & Intermediate & $65(16.3 \%)$ \\
\hline \multirow{3}{*}{ Self-care } & Low & $274(68.5 \%)$ \\
\cline { 2 - 3 } & High & $126(31.5 \%)$ \\
\hline
\end{tabular}

Five items with factor loading $<0.4$ or those collected under two different factors with high factor loading were excluded. After the exclusion of mentioned items, the KMO test was re-administered. Results from this test showed the value of 0.76 . Results from factor analysis for the constructed scale were in form of three factors with 11 items. The factor loading ranged from 0.46 to 0.78 . These three factors together could explain $40.28 \%$ of the total variance. Based on the existing items in each factor, the factor 1 with four items was named the "lateral effects," which explained $14.97 \%$ of the variance. Factor 2 with three items was named "patient's diagnosis barriers," which explained $13.18 \%$ of the variance. Factor 3 with four items was named "facilities and resources," which explained $12.12 \%$ of the variance (Table 2 ).

Table 2. Factor Loadings of Scale

\begin{tabular}{|l|l|l|l|l|l|}
\hline $\begin{array}{l}\text { Factor 1 (Eigenvalue }=1.64, \\
\text { Variance\%=14.97) }\end{array}$ & \multicolumn{2}{l|}{$\begin{array}{l}\text { Factor 2 (Eigenvalue }=1.45, \\
\text { Variance\%=13.18) }\end{array}$} & \multicolumn{2}{l|}{$\begin{array}{l}\text { Factor 3 (Eigenvalue }=1.33, \\
\text { Variance\% = 12.12) }\end{array}$} \\
\hline IN & FL & IN & FL & IN $^{*}$ & FL $^{* *}$ \\
\hline 6 & 0.76 & 1 & 0.78 & 11 & 0.70 \\
\hline 5 & 0.62 & 7 & 0.63 & 8 & 0.60 \\
\hline 2 & 0.55 & 4 & 0.62 & 10 & 0.57 \\
\hline 3 & 0.46 & & & 9 & 0.46 \\
\hline
\end{tabular}

${ }^{*}$ IN: Item Number, ${ }^{* *}$ FL: Factor loading 
The reliability of the instrument was measured through Cronbach's alpha for the whole questionnaire and each item, after performing the factor analysis. The internal consistencies of each factor, as well as the correlation of each item with the total items are presented in Table 3 . The overall reliability coefficient of the instruments was 0.79 , ranging from 0.82 to 0.93 for each factor (Table 4 ).

Table 3. Cronbach's Alpha Reliability Coefficients and Item-total Correlations of the of perceived barriers Questionnaire

\begin{tabular}{|c|c|c|c|c|c|}
\hline & Questions on Perceived Barriers & $\mathrm{M}^{*} \pm \mathrm{SD}^{* *}$ & $\begin{array}{l}\text { Total } \\
\text { Correlation }\end{array}$ & $\begin{array}{l}\text { Squared Multiple } \\
\text { Correlation }\end{array}$ & $\begin{array}{l}\alpha \text { If Item } \\
\text { Deleted }\end{array}$ \\
\hline 1 & $\begin{array}{l}\text { The provided guidance and information about } \\
\text { my disease do not fit my knowledge and } \\
\text { understanding }\end{array}$ & $2.56 \pm 1.30$ & 0.42 & 0.32 & 0.73 \\
\hline 2 & $\begin{array}{l}\text { Physical problems inhibit me from } \\
\text { performing appropriate self-care activities by } \\
\text { taking exercise }\end{array}$ & $2.22 \pm 1.20$ & 0.43 & 0.35 & 0.75 \\
\hline 3 & $\begin{array}{l}\text { Fatigue because of a long-term infection and } \\
\text { treatment inhibits me from performing } \\
\text { appropriate self-care activities }\end{array}$ & $2.03 \pm 1.19$ & 0.41 & 0.31 & 0.78 \\
\hline 4 & $\begin{array}{l}\text { Missing my medication inhibits me from } \\
\text { performing appropriate self-care activities }\end{array}$ & $2.47 \pm 1.25$ & 0.39 & 0.29 & 0.71 \\
\hline 5 & $\begin{array}{l}\text { My dependence on children or family in } \\
\text { performing some activities inhibits me from } \\
\text { performing appropriate self-care activities }\end{array}$ & $2.92 \pm 1.26$ & 0.48 & 0.39 & 0.72 \\
\hline 6 & $\begin{array}{l}\text { The shame of taking medication inhibits me } \\
\text { from performing appropriate self-care } \\
\text { activities }\end{array}$ & $3.02 \pm 1.26$ & 0.43 & 0.38 & 0.77 \\
\hline 7 & $\begin{array}{l}\text { Incapability in changing my life style inhibit } \\
\text { me from performing appropriate self-care } \\
\text { activities }\end{array}$ & $2.98 \pm 1.28$ & 0.43 & 0.41 & 0.70 \\
\hline 8 & $\begin{array}{l}\text { Limited facilities and financial problems } \\
\text { inhibit me from performing appropriate self- } \\
\text { care activities }\end{array}$ & $1.26 \pm 0.58$ & 0.46 & 0.29 & 0.78 \\
\hline 9 & $\begin{array}{l}\text { Devoting insufficient time by the doctor } \\
\text { inhibits me from performing appropriate self- } \\
\text { care activities }\end{array}$ & $2.81 \pm 1.28$ & 0.46 & 0.28 & 0.77 \\
\hline 10 & $\begin{array}{l}\text { Inaccessibility to Glucose Meter inhibits me } \\
\text { from performing appropriate self-care } \\
\text { activities }\end{array}$ & $2.80 \pm 1.30$ & 0.52 & 0.37 & 0.69 \\
\hline 11 & $\begin{array}{l}\text { Inadequate motivation of doctor inhibits me } \\
\text { from performing appropriate self-care } \\
\text { activities }\end{array}$ & $2.68 \pm 1.41$ & 0.46 & 0.33 & 0.71 \\
\hline
\end{tabular}

${ }^{*} \mathrm{M}=$ Mean, ${ }^{* *} \mathrm{SD}=$ Standard Deviation

Table 4. Cronbach's Alpha Reliability Coefficients and Item-total Correlations of the Sub Scales

\begin{tabular}{|l|l|l|l|}
\hline Factor & Score & $\mathrm{A}^{*}$ & $\mathrm{r}^{* *}$ \\
\hline Lateral effects & $2.54 \pm 0.61$ & 0.73 & $0.51-.70$ \\
\hline Patient's diagnosis barriers & $2.67 \pm 0.81$ & 0.78 & $0.55-.74$ \\
\hline Facilities and resources & $2.39 \pm 0.60$ & 0.80 & $0.60-.81$ \\
\hline
\end{tabular}

${ }^{*} \mathrm{~A}$ : Alpha values ${ }^{* *}$ r: Item-total correlation

In this study, the mean scores of the barriers perceived by the patients with high and low self-care were compared. The mean score of self-care was $3.05 \pm 0.29$ in all patients. According to the results, patients with high self-care score obtained lower mean score in the scale of perceived barriers than the patients with low self-care scores. Between-group comparison of all items showed that the patients with appropriate self-care obtained lower mean 
score in nine items ( $81 \%$ of the overall items). This implies an inverse relationship between self-care and perceived barriers (Table 5).

Table 5. Normative data on all items according to self-care group

\begin{tabular}{|c|c|c|c|c|c|}
\hline & \multirow[t]{3}{*}{ Questions on Perceived Barriers } & \multicolumn{4}{|c|}{ Self-Care } \\
\hline & & \multicolumn{2}{|c|}{ Enough } & \multicolumn{2}{|c|}{ Not Enough } \\
\hline & & $\mathrm{M}^{*}$ & $\mathrm{SD}^{* *}$ & $\mathrm{M}$ & SD \\
\hline 1 & $\begin{array}{l}\text { The provided guidance and information about my disease do not fit my } \\
\text { knowledge and understanding. }\end{array}$ & 2.45 & 1.29 & 2.80 & 1.30 \\
\hline 2 & $\begin{array}{l}\text { Physical problems inhibit me from performing appropriate self-care } \\
\text { activities by taking exercise. }\end{array}$ & 2.21 & 1.24 & 2.25 & 1.13 \\
\hline 3 & $\begin{array}{l}\text { Fatigue because of a long-term infection and treatment inhibits me from } \\
\text { performing appropriate self-care activities }\end{array}$ & 2.04 & 1.24 & 2.00 & 1.06 \\
\hline 4 & $\begin{array}{l}\text { Missing my medication inhibits me from performing appropriate self-care } \\
\text { activities. }\end{array}$ & 2.44 & 1.28 & 2.53 & 1.19 \\
\hline 5 & $\begin{array}{l}\text { My dependence on children or family in performing some activities } \\
\text { inhibits me from performing appropriate self-care activities. }\end{array}$ & 2.91 & 1.24 & 2.92 & 1.31 \\
\hline 6 & $\begin{array}{l}\text { The shame of taking medication inhibits me from performing appropriate } \\
\text { self-care activities. }\end{array}$ & 2.99 & 1.30 & 3.07 & 1.17 \\
\hline 7 & $\begin{array}{l}\text { Incapability in changing my life style inhibit me from performing } \\
\text { appropriate self-care activities. }\end{array}$ & 2.95 & 1.29 & 3.03 & 1.26 \\
\hline 8 & $\begin{array}{l}\text { Limited facilities and financial problems inhibit me from performing } \\
\text { appropriate self-care activities. }\end{array}$ & 1.22 & 0.51 & 1.34 & 0.70 \\
\hline 9 & $\begin{array}{l}\text { Devoting insufficient time by the doctor inhibits me from performing } \\
\text { appropriate self-care activities. }\end{array}$ & 2.67 & 1.29 & 3.11 & 1.23 \\
\hline $\begin{array}{l}1 \\
0\end{array}$ & $\begin{array}{l}\text { Inaccessibility to Glucose Meter inhibits me from performing appropriate } \\
\text { self-care activities. }\end{array}$ & 2.76 & 1.31 & 2.92 & 1.28 \\
\hline $\begin{array}{l}1 \\
1\end{array}$ & $\begin{array}{l}\text { Inadequate motivation of doctor inhibits me from performing appropriate } \\
\text { self-care activities. }\end{array}$ & 2.83 & 1.39 & 2.34 & 1.41 \\
\hline
\end{tabular}

${ }^{*} \mathrm{M}=$ Mean,${ }^{* *} \mathrm{SD}=$ Standard Deviation

\section{Discussion}

Barriers are most often considered as inhibitors or personal expenses against a certain behavior. They usually discourage the acquisition of a certain behavior. In other words, under a poor preparation for an action and large number of barriers, that action will never happen. The perceived barriers directly affect the health behaviors by inhibiting the action; in addition, they indirectly affect the planning for an action by reducing commitment and devotion (17).

This study developed and investigated the scale of perceived barriers to self-care in Iranian patients with type 2 diabetes. According to the researchers, despite investigation into the perceived barriers in some diabetes self-care studies in Iran, it has been rarely done with a reliable and valid instrument. It can be said that this instrument is one of the first ones developed for assessing the perceived barriers to self-care in Iranian patients with type 2 diabetes. The self-reporting scale of perceived barriers includes 11 items elicited from a vast literature review. Results implied that there was acceptable reliability of this scale in investigating the perceived barriers to self-care in Iranian patients with diabetes. In addition, the degree of internal consistency showed that this instrument produces stable scores over time.

The important principle in self-care is cooperation and responsibility of the patient. In that, performing self-care activity correctly can control several disease complications. The perceived barriers refer to the beliefs about the actual and expected costs of commitment to the new behavior. In other words, it encompasses the potential negative aspects perceived as a barrier against a certain behavior $(18,19)$. According to the exploratory factor analysis, these aspects in this instrument are categorized as barriers caused by side effects of the disease, patient's diagnosis barriers, and barriers related to facilities and resources. The barriers caused by the side effects of the disease include negative aspects perceived by the patient as barriers against self-care behaviors. In this instrument, the shame of taking medication, dependence on children or family because of disease, physical problems inhibiting exercise, and 
fatigue because of a long-term infection and treatment were considered as investigated barrier factors caused by side effects of the disease. In different studies, diabetes-related factors have been considered as one of the most important barriers perceived against diabetes self-care activities. According to these studies, impatience and reluctance ranked first, followed by over-exhaustion and physical problems. Regarding the nature of diabetes, this result seems natural and rational $(20,21)$.

According to the factor analysis, the second factor in terms of perceived barriers against diabetes self-care activities is patient's diagnosis barriers. Three items, namely lack of understanding of provided guidance and information, disremembering, and incapability of changing life style, are categorized in this factor. Daniel et al. believed that this group of perceived barriers has an important role in diabetes self-care activities (20). The third class belongs to facility- and resource-related barriers. In this section, peoples' perceptions of available resources or time were investigated. All of these cases, as barriers, negatively affect one's self-care behavior $(22,23)$.

Validity of the final scale in this study showed that the score of perceived barriers was lower in patients with appropriate self-care activities than in those with inappropriate behaviors. Empirical studies have shown that the predicted barriers frequently affect the intention for showing a certain behavior and its actual exhibition. Among the studies of health improvement models, $79 \%$ of them regarded experimental support as a determining factor in health-improving behaviors (24).

Similar to other studies, this research had a number of limitations. Despite a large quantity of patients with hypertension visiting health centers, they cannot be generalized to all patients with this problem. Due to the nature of this cross-sectional study, it is not possible to consider a specific cause-effect relationship between the perceived barriers and self-care in diabetic patients; therefore, the existing correlation just indicates that there is a relationship. This necessitates prospective and follow-up studies to investigate this relationship. The three-factor structure of the perceived barriers in this instrument indicated the need for a confirmatory factor analysis in future studies. In addition, performing further studies with a larger sample size and the stratified sampling method can improve the discriminating validity of the study.

\section{Conclusions}

According to the results, the developed scale is a valid and reliable instrument for examining the barriers perceived by the patients. This instrument can be used in cross-sectional studies to assess the prediction capability of perceived barriers against self-care. It also can be employed in interventional studies to inspect the effects of experimental interventions.

\section{Acknowledgments:}

This study was conducted as part of a research project related to a $\mathrm{PhD}$ dissertation with financial support of Shahid Beheshti University of Medical Sciences (code number 1393-1-85-13790) and with the collaboration of the medical teams in the diabetes units of Isfahan's health centers. We also appreciate all authorities and participating patients.

\section{Conflict of Interest:}

There is no conflict of interest to be declared.

\section{Authors' contributions:}

All authors contributed to this project and article equally. All authors read and approved the final manuscript.

\section{References}

1) Danaei G, Finucane MM, Lu Y, Singh GM, Cowan MJ, Paciorek CJ, et al. National, regional, and global trends in fasting plasma glucose and diabetes prevalence since 1980: systematic analysis of health examination surveys and epidemiological studies with 370 country-years and 2.7 million participants. The Lancet. 2011;378(9785):31-40. doi: 10.1016/S0140-6736(11)60679-X

2) Inzucchi S, Bergenstal R, Buse J, Diamant M, Ferrannini E, Nauck M, et al. Management of hyperglycaemia in type 2 diabetes: a patient-centered approach. Position statement of the American Diabetes Association (ADA) and the European Association for the Study of Diabetes (EASD). Diabetologia. 2012;55(6):1577-96. doi: 10.1007/s00125-012-2534-0 
3) Inzucchi SE, Bergenstal RM, Buse JB, Diamant M, Ferrannini E, Nauck M, et al. Management of hyperglycemia in type 2 diabetes: a patient-centered approach position statement of the American Diabetes Association (ADA) and the European Association for the Study of Diabetes (EASD). Diabetes care. 2012;35(6):1364-79.doi: 10.2337/dc12-0413

4) Funnell MM, Brown TL, Childs BP, Haas LB, Hosey GM, Jensen B, et al. National standards for diabetes self-management education. Diabetes care. 2011;34(Supplement 1):S89-S96. doi: 10.2337/dc09-S087

5) Trief PM, Izquierdo R, Eimicke JP, Teresi JA, Goland R, Palmas W, et al. Adherence to diabetes self care for white, African-American and Hispanic American telemedicine participants: 5 year results from the IDEATel project. Ethn Health. 2013;18(1):83-96. doi: 10.1080/13557858.2012.700915

6) Shrivastava S, Shrivastava PS, Ramasamy J. Role of self-care in management of diabetes mellitus. J Diabetes Metab Disord. 2013;12(1):14. doi: 10.1186/2251-6581-12-14.

7) Sigurðardóttir ÁK. Self-care in diabetes: model of factors affecting self-care. JCN. 2005;14(3):301-14. PMID: 15707440

8) Jones H, Edwards L, Vallis TM, Ruggiero L, Rossi SR, Rossi JS, et al. Changes in diabetes self-care behaviors make a difference in glycemic control the diabetes stages of change (DiSC) study. Diabetes care. 2003;26(3):732-7. PMID: 12610030

9) Irvine AA. Self care behaviors in a rural population with diabetes. PEC. 1989;13(1):3-13. doi: 10.1016/0738-3991(89)90065-7

10) Simmons D, Lillis S, Swan J, Haar J. Discordance in perceptions of barriers to diabetes care between patients and primary care and secondary care. Diabetes Care. 2007;30(3):490-5. PMID: 17327310

11) O'dea JA. Why do kids eat healthful food? Perceived benefits of and barriers to healthful eating and physical activity among children and adolescents. Journal of the American Dietetic Association. 2003;103(4):497-501. PMID: 12669014

12) Williams B, Brown T, Onsman A. Exploratory factor analysis: A five-step guide for novices. Australasian Journal of Paramedicine. 2012;8(3):1.

13) Toobert DJ, Hampson SE, Glasgow RE. The summary of diabetes self-care activities measure: results from 7 studies and a revised scale. Diabetes care. 2000;23(7):943-50. PMID: 10895844

14) Aalto A-M, Uutela A. Glycemic control, self-care behaviors, and psychosocial factors among insulin treated diabetics: a test of an extended health belief model. IJBM. 1997;4(3):191-214. PMID:16250728

15) Polit DF, Beck CT. The content validity index: are you sure you know what's being reported? Critique and recommendations. RINAH. 2006;29(5):489-97. PMID: 16977646

16) Santos JRA. Cronbach's alpha: A tool for assessing the reliability of scales. Journal of extension. 1999;37(2):1-5.

17) Brekke HK, Sunesson $\AA$, Axelsen M, Lenner R. Attitudes and barriers to dietary advice aimed at reducing risk of type 2 diabetes in first-degree relatives of patients with type 2 diabetes. Journal of human nutrition and dietetics. 2004;17(6):513-21. PMID:15546428

18) Rafique G, Shaikh F. Identifying needs and barriers to diabetes education in patients with diabetes. Age (years). J Pak Med Assoc. 2006;18(30):31-50. PMID:16967784

19) Charron-Prochownik D, Sereika SM, Becker D, Jacober S, Mansfield J, White NH, et al. Reproductive health beliefs and behaviors in teens with diabetes: application of the Expanded Health Belief Model. Pediatric Diabetes. 2001;2(1):30-9. PMID: 15016208

20) Daniel M, Messer LC. Perceptions of disease severity and barriers to self-care predict glycemic control in Aboriginal persons with type 2 diabetes mellitus. Chronic Diseases and Injuries in Canada. 2002;23(4):130. PMID: 12517320

21) Nagelkerk J, Reick K, Meengs L. Perceived barriers and effective strategies to diabetes self-management.JAN. 2006;54(2):151-8. PMID: 16553701

22) Tan MY. The relationship of health beliefs and complication prevention behaviors of Chinese individuals with Type 2 Diabetes Mellitus. Diabetes research and clinical practice. 2004;66(1):71-7. PMID:15364164

23) Koch J. The Role of Exercise in the African-American Woman with Type 2 Diabetes Mellitus: Application of the Health Belief Model. Journal of the American Academy of Nurse Practitioners. 2002;14(3):126-30. PMID: 11924335

24) Baker D. Health Promotion in Nursing Practice. Family \& Community Health. 2007;30(1):85-6 